\title{
CARACTERIZAÇÃO DO RENDIMENTO E QUANTIFICAÇÃO DOS RESÍDUOS GERADOS EM SERRARIA ATRAVÉS DO BALANÇO DE MATERIAIS
}

\author{
Martha Andreia Brand \\ Graciela Inês Bolzon de Muñiz ${ }^{2}$ \\ Dimas Agostinho da Silva ${ }^{2}$ \\ Umberto Klock ${ }^{2}$
}

\begin{abstract}
RESUMO
Este trabalho objetivou a caracterização do rendimento e quantificação dos resíduos gerados em uma serraria, sendo desenvolvido na Empresa Battistella Indústria e Comércio Ltda. (Rio Negrinho, SC), composta por uma laminadora, serraria e manufatura de painéis. Foram realizadas visitas e elaborados questionários para avaliação dos dados existentes, que foram distribuídos em uma série histórica, desde janeiro de 1998 a julho de 1999. As determinações foram feitas com base no balanço de materiais. Foi elaborado um fluxograma da linha produtiva, de onde se pôde obter os valores do rendimento do desdobro $(34,87 \%)$, da secagem $(81,88 \%)$ e da classificação da madeira $(86,42 \%)$. O rendimento geral foi de $38,62 \%$ e o consumo de matéria-prima foi de $2,62 \mathrm{~m}^{3}$ de toras com casca $/ \mathrm{m}^{3}$ de madeira serrada seca e classificada. Daí conclui-se que o rendimento do desdobro é baixo, bem inferior ou encontrado em literatura; o rendimento geral está mais próximo de valores já publicados; o resíduo tem grande potencialidade de utilização devido a separação do mesmo durante o processo produtivo e o estabelecimento do fator de conversão de toras em madeira serrada possibilita o planejamento do volume de matéria-prima necessário para o desdobro e do volume de resíduo gerado em um período pré-estabelecido.

Palavras chave: serraria, processo produtivo, balanço de materiais, rendimento
\end{abstract}

\section{YIELD AND WASTE PRODUCTION CARACTERIZATION IN SAWMILL THROUGH MATERIAL BALANCE}

\begin{abstract}
This paper is an attempt to characterize the yield and wood waste produced during the productive process of one of the sawmill, located in Rio Negrinho, Santa Catarina, Brazil (Battistella Indústria e Comércio Ltda.). The data analysis was carried out based on the material balance and on the production yield. The study pointed out the following results: unroll yield (34,87\%); drying (81,88\%); lumber classification $(86,42 \%)$; general yield $(38,62 \%)$ although low, it is in accordance with normal values; consumption of raw material of $2,62 \mathrm{~m}^{3}$ of $\operatorname{logs}$ with bark $/ \mathrm{m}^{3}$ of lumber. The result also indicate that the wood waste has potenciality to utilization because it is separated during the process and the convertion factor of the log in lumber is very important to the development of the activities.
\end{abstract}

Key-words: lumber, material balance, sawmill, yield

\section{INTRODUÇÃO}

As indústrias de base florestal têm baixo rendimento e geram grande quantidade de resíduos no processo produtivo, principalmente as indústrias de transformação primária. $\mathrm{O}$ aumento progressivo da quantidade de madeira desdobrada tem revelado problemas como o crescimento do consumo da matéria-prima madeira, em um momento que o mercado apresenta diminuição de oferta da mesma, além da disponibilização de quantidades ainda maiores de resíduos, que muitas vezes não tem utilização na indústria, onde os mesmos foram gerados.

Aliado a isto, a disponibilização dos resíduos sem uma destinação adequada gera graves problemas ambientais como $\mathrm{o}$

\footnotetext{
${ }^{1}$ martha@uniplac.rct-sc.br. Eng ${ }^{0}$ Florestal, M.Sc., Prof. ${ }^{\text {a }}$ Dpto de Ciências Exatas e Tecnológicas, UNIPLAC

2 gbmunize@ufpr.br; dimass@ floresta.ufpr.br; klockuer@ floresta.ufpr.br. Eng ${ }^{\circ}$ Florestal, Prof. Dpto de Eng. e Tecnologia Florestal, UFPR
} 
assoreamento e poluição dos rios, poluição do ar devido a queima para a eliminação dos mesmos, utilização de áreas para o armazenamento deste material que poderiam ser destinadas para outros fins, e o desperdício da matéria-prima que entra na indústria.

A forma mais adequada do conhecimento necessário para a solução destes problemas passa pela caracterização do rendimento produtivo das indústrias, dos fatores geradores de resíduos, do volume e tipos de resíduos existentes, da sazonalidade de geração dos mesmos, além dos possíveis usos que podem ser dados a este material. Sendo assim, é fundamental a realização da análise de cada fase do processo produtivo, caracterizado pelo balanço de materiais e pela avaliação do rendimento. Nesta avaliação é possível diagnosticar todas as entradas e saídas do processo tendo como resposta à determinação das quantidades de produtos manufaturados e resíduos gerados.

Desta forma, este trabalho teve como objetivo caracterizar o rendimento e quantificar os resíduos gerados durante as fases do processo produtivo de uma serraria de grande porte, através do estabelecimento de uma metodologia que tenha como base à aplicação dos princípios do balanço de materiais e da fórmula clássica do rendimento.

\section{REFERÊNCIAS}

\section{Métodos de determinação do rendimento da madeira serrada}

Segundo Tuset \& Duran (1979)

existem basicamente dois modos de avaliar o rendimento na operação de desdobro. A primeira forma básica de medir o rendimento de madeira serrada é mediante o cálculo da produtividade em cada máquina e no conjunto dos equipamentos. A forma tradicional de expressar a produtividade de uma serra é em $\mathrm{m}^{3}$ de madeira serrada por hora ou $\mathrm{m}^{3} \mathrm{de}$ madeira serrada por hora/homem.

É possível também se fazer uma "estimativa do rendimento de madeira serrada por tora", que é significativamente relacionada ao coeficiente de transformação e em alguns casos é muito importante na comercialização de madeira roliça ou para cálculos complementares de inventários florestais.
Existem no mundo inúmeras fórmulas para a determinação desta estimativa e algumas das mais conhecidas são: cubagem em quarto sem dedução; cubagem em quarto deduzido; cubagem em sexto deduzido; cubagem em quarto não deduzido em pés; cubagem Hopuus, etc.

A segunda forma de determinação do rendimento, também citada por Rocha (1999), é a determinação do coeficiente de transformação ou fator de rendimento, que é a relação entre o volume de madeira serrada que se obtém e o volume de toras que são usadas para o processamento. Esta unidade pode ser expressa em unidade métrica e em pés, e em ambos os casos o coeficiente é dado em porcentagem. Assim:

Coeficiente de transformação $=$

$$
\frac{\mathrm{m}^{3} \text { de madeira serrada }}{\mathrm{m}^{3} \text { de madeira em toras }}
$$

Rocha (1999) considera ainda que, além da essência que está sendo desdobrada, outros fatores afetam o rendimento como a qualidade dos povoamentos de onde as árvores são provenientes, os equipamentos e técnicas utilizados no desdobro e a qualidade profissional dos operários.

O trabalho aqui proposto apresentado utilizou a segunda forma de determinação do rendimento para atender os objetivos propostos, adequando a fórmula às diferentes etapas do processo produtivo.

\section{Resíduos na indústria de base florestal}

Segundo C.T. Donovan Associates INC. (1990), os resíduos madeiráveis podem ser divididos em três categorias. A primeira é composta por resíduos silviculturais, também denominados como a madeira resultante da operação de colheita ou resíduos de biomassa. Consistem de árvores inteiras transformadas em partículas (cavacos); copa, galhos e ramos produzidos durante o manejo e práticas de transformação da árvore em toras.

A segunda categoria é composta por resíduos de conversões "in situ", que consistem de árvores inteiras transformadas em partículas; copas, galhos e ramos obtidos de conversões localizadas em rodovias, casas, comércios, indústrias e outras atividades desenvolvidas com a utilização de madeira.

A última é composta por resíduos de 
madeira, definidos como resíduos industriais, que incluem casca, partículas, destopos, serragem e restos gerados como resíduo das indústrias primária e secundária de produtos de madeira e outras indústrias, comércios e atividades residenciais.

Hoop et al (1997) concorda com o autor anterior na definição dos resíduos industriais de madeira e reforça que a disponibilização deste material acarreta problemas de poluição do ar e da água, sendo que uma solução comum de gerenciamento do resíduo é através do uso do mesmo como combustível.

Considerando que os resíduos madeiráveis industriais são muito heterogêneos, em termos de formas e características físicas, são gerados em diferentes locais dentro da indústria e que a quantidade disponibilizada é um dos fatores que determinam sua potencialidade de uso, é muito importante à avaliação da potencialidade da indústria em termos de geração e utilização dos mesmos.

Outro fator importante na análise dos resíduos é a questão econômica para a determinação dos custos da falta de utilização e necessidade de alocação e os benefícios da utilização.

\section{Geração de resíduos na indústria}

A conversão de toras em tábuas, pranchas, vigas ou outras peças de madeira implica, necessariamente, na produção de uma quantidade maior ou menor de desperdício, segundo os fatores que influem no seu volume, como a natureza da matéria-prima, a eficiência das máquinas empregadas pela indústria e as exigências do mercado. Este último aspecto exerce influência através das quantidades relativas de madeira serrada de diversas espessuras e comprimentos solicitados, já que, por exemplo, a obtenção de tábuas mais finas requer maior quantidade de cortes, o que aumenta o desperdício em forma de serragem (Anuário Brasileiro de Economia Florestal, 1957).

Estimativas grosseiras dos resíduos disponíveis podem ser feitas através das áreas florestais produtivas, da sua produção primária e do grau de rendimento. Para os resíduos nas diferentes indústrias madeireiras, a disponibilidade pode ser determinada diretamente das estatísticas disponíveis ou pela relação input matéria-prima/output produtos
(Patzak, 1977), ou ainda pela diferença entre a quantidade de matéria-prima que entra e a quantidade de produto que sai do processo, sendo este último o princípio do balanço de materiais.

\section{Aproveitamento dos resíduos industriais}

Os resíduos florestais ou madeiráveis, além de serem utilizados para a geração de energia de diversas formas como queima direta, briquetes de madeira, carvão, briquetes de carvão e pellets, pode também ser utilizados de várias outras maneiras como na fabricação de pequenos objetos e utensílios tais como brinquedos, artigos de copa/cozinha, cabos de ferramentas, artigos desportivos, decorativos e de recreação; produção de chapas de partículas de diferentes composições; cama para aviários, currais e estábulos; compostagem para adubação e complementos orgânicos para o solo; produção de fibras para diversos fins tais como chapas, isolamento termo-acústico, papel, papelão; produção de pacotes para contenção de encostas; obtenção de matériaprima para a indústria de tintas, vernizes, corantes, adesivos, indústria alimentícia e solvente através da extração de voláteis, etc (Souza, 1997), ou ainda no paisagismo de jardins (National Association of Forest Industries, 1999).

As partículas de madeira ou resíduos que são utilizados para os usos anteriormente citados podem ser originários de muitas fontes, e entre elas as florestas nativas, plantações e resíduos de serrarias (National Association of Forest Industries, 1999).

O resíduo gerado em serrarias é uma importante matéria-prima em forma de partículas para a produção de polpa e produtos como chapas de partículas. É efetivamente usado como matéria-prima em plantas de produção de combustíveis de madeira, como cama para cultivo de cogumelos, e o restante é consumido em queima direta. A casca é usada como matéria-prima para produção de combustíveis de madeira, mas é parcialmente queimada sem aproveitamento energético ou abandonada (Miyazaki, 1989).

\section{Produção de resíduos nas indústrias de processamento primário da madeira}

As indústrias de processamento primário da madeira são empresas que usam a tora inteira para gerar produtos como pranchas 
e vigas. Os produtos são industrializados depois que as toras são desgalhadas, destopadas e serradas. Baseado nesta definição, os resíduos produzidos por estas indústrias são considerados sólidos, não necessitando assim de manuseio especial ou equipamentos para isso. Os mesmos são produzidos em grande quantidade durante os processos de manufatura e podem ser classificados em partículas, serragem, casca, refilos e destopos, e uma variação de combinações destes (C.T.Donovan Associates Inc, 1990).

A tabela 1 apresenta uma comparação entre os resultados obtidos por Miyazaki (1989) e Olandoski et al (1997) em serrarias que desdobram madeiras de coníferas, respectivamente nos Estados Unidos e Brasil.

Tabela 1: Produção de resíduos em serrarias de coníferas nos Estados Unidos e Brasil

Table 1: $\quad$ Production of wood waste in softwood sawmill in the United States and Brazil

Tipos de resíduos gerados (\%)

\begin{tabular}{ccccc}
\hline País & Refilo & Destopo & Pó-de-lixa e serragem & Casca e outros resíduos \\
\hline EUA & 14,40 & 1,60 & 8,50 & 6,70 \\
Brasil & 24,00 & 3,00 & 10,00 & 12,00 \\
\hline
\end{tabular}

Fonte dos dados: Miyazaki (1989) E Olandoski et al (1997).

Através da tabela 1 pode-se perceber que quando a maior influência na geração de resíduos é dos equipamentos de corte (espessura dos dentes das serras) a diferença na quantidade de obtida entre os dois países não é tão acentuada. Porém, quando as operações dependem mais do treinamento dos operadores (refilo e destopo), e qualidade da matériaprima (casca e outros resíduos), a quantidade de resíduos no Brasil pode chegar ao dobro dos Estados Unidos.

Nesta linha de pesquisa, Kock (1976) foi além, pois quantificou os resíduos gerados na manufatura de madeira serrada aplainada de coníferas para uso em construção de casas e qualificou os resíduos para usos potenciais, como pode ser observado na figura 1 .

\begin{tabular}{|c|c|c|}
\hline & \multirow{5}{*}{$\Rightarrow$} & $\begin{array}{c}0,35 \text { t de madeira serrada aplainada } \\
\text { (dois topos acabados) }\end{array}$ \\
\hline & & $\begin{array}{l}\text { 0,29 t de partículas } \\
\text { (uso-polpa) }\end{array}$ \\
\hline \multirow[t]{3}{*}{$1 \mathrm{t}$ de toras com casca (coníferas) } & & \\
\hline & & $\begin{array}{l}\text { 0,15 t de partículas tipo "shaving" } \\
\text { (uso - chapas de partículas) }\end{array}$ \\
\hline & & $\begin{array}{l}0,21 \text { t de casca e serragem } \\
\text { (uso - combustível) }\end{array}$ \\
\hline
\end{tabular}

Figura 1: Fluxograma do rendimento em madeira serrada aplainada a partir de toras com casca (madeira de coníferas) (fonte dos dados: Kock (1976))

Figure 1: $\quad$ Lumber yield taken from log with bark (Softwood) (Kock (1976)

De maneira geral, para a manufatura de uma tonelada seca de madeira de conífera serrada são necessárias 2,86 toneladas secas de toras com casca Kock (1976).

\section{MATERIAIS E MÉTODOS}

O trabalho foi desenvolvido na Empresa Battistella Indústria e Comércio Ltda, localizada na região norte do Estado de Santa Catarina. As instalações industriais estão situadas à margem direita da rodovia BR 280, $\mathrm{Km}$ 133, aproximadamente $10 \mathrm{~km}$ da cidade de Rio Negrinho.

Devido a diversidade de produtos, a indústria é composta por uma laminadora e uma serraria que são responsáveis pela produção de lâminas e madeira serrada destinadas à venda ou como matéria-prima para o setor de painéis laminados e sarrafeados. Além destes, existe um setor responsável pela geração de energia térmica e elétrica que supre as necessidades do processo produtivo.

A indústria utiliza somente madeira de florestas plantadas, e a matéria-prima restringese à madeira de espécies do gênero Pinus, principalmente Pinus taeda L. e Pinus elliottii var. elliottii Engelm.

Como mencionado, apesar da indústria ser composta por vários setores produtivos, este 
trabalho limitou-se a avaliação do rendimento e quantificação dos resíduos gerados na serraria.

\section{Descrição do processo produtivo}

A serraria, na ocasião da coleta de dados, era composta por três linhas produtivas denominadas de Serraria de Tora Grossa (TG) com desdobro médio de 10.500 toneladas/mês de toras e duas Serrarias de Toras Finas com desdobro médio de 12.000 toneladas/mês de toras. $\mathrm{O}$ volume de madeira serrada produzido pelas serrarias é determinado pelas solicitações do setor comercial e pelas necessidades do setor de manufatura de painéis, porém é em média de $5000 \mathrm{~m}^{3} / \mathrm{mês}$ para a serraria de toras grossas e $4000 \mathrm{~m}^{3} /$ mês para as serrarias de toras finas. Nas linhas produtivas, de forma geral, as bitolas serradas são 25, 32 e $38 \mathrm{~mm}$ de espessura.

A composição, em termos de equipamentos, das três linhas produtivas está representada na tabela 2 .

Tabela 2: Equipamentos e atividades componentes da serraria

Table 2: $\quad$ Sawmill equipment and activities

\begin{tabular}{|c|c|c|}
\hline \multicolumn{3}{|c|}{ Serraria de Toras Grossas (TG) } \\
\hline Equipamento ou atividade & Quantidade & Descrição \\
\hline Serra de fita dupla & 01 & Primeira serra de desdobro. Retira duas costaneiras \\
\hline Serra de fita simples & 03 & $\begin{array}{l}\text { Uma serra de fita de } 3^{\text {a }} \text { face (retirada da terceira costaneira) e } \\
\text { duas serras de fita de reaproveitamento }\end{array}$ \\
\hline Serra de fita quádrupla & 02 & Última serra de desdobro. Obtenção de tábuas \\
\hline Serra circular dupla & 01 & Refilo das tábuas de reaproveitamento \\
\hline Serra circular pendular & 02 & Destopo das tábuas de reaproveitamento \\
\hline Setor de montagem de pilhas & 01 & Preparação das pilhas para secagem \\
\hline Secador de madeira ${ }^{1}$ & 07 & Secagem da madeira \\
\hline Picador de tambor ${ }^{2}$ & 01 & $\begin{array}{l}\text { Transformação dos resíduos da laminadora e serrarias em } \\
\text { cavacos para geração de energia }\end{array}$ \\
\hline Picador com rotor & 01 & Produção de cavacos, vendidos para celulose \\
\hline Correia transportadora de resíduos ${ }^{3}$ & 04 & $\begin{array}{l}\text { Coleta e transporte de resíduos gerados durante o processo de } \\
\text { desdobro (TG e TFs) }\end{array}$ \\
\hline \multicolumn{3}{|c|}{ Serrarias de Toras Finas (TFs) } \\
\hline Descascador de tambor & 01 & Alimenta as duas serrarias com toras sem casca \\
\hline Serra de fita dupla & 02 & Uma serra em cada serraria. Retirada de duas costaneiras \\
\hline Serra circular múltipla de dois eixos & 02 & Uma em cada serraria. Obtenção de tábuas \\
\hline Setor de montagem de pilhas & 02 & Uma em cada serraria. Preparação das pilhas para secagem \\
\hline \multicolumn{3}{|c|}{ 1: Os secadores atendem as três linhas de produção } \\
\hline \multicolumn{3}{|c|}{ 2: Equipamentos utilizados tanto para atender as serrarias TG como TF } \\
\hline \multicolumn{3}{|c|}{$\begin{array}{l}\text { 3: Ao final das linhas produtivas, as correias transportadoras das serrarias e laminadora convergem para uma correia que } \\
\text { coleta todo o resíduo gerado e leva ao picador de tambor. }\end{array}$} \\
\hline
\end{tabular}

A serraria de toras grossas desdobra toras com diâmetros entre 18 e $28 \mathrm{~cm}$, sendo que os produtos desta linha produtivos são tábuas sem destopo que saem da última serra de fita quádrupla e tábuas destopadas e refiladas oriundas das serras de reaproveitamento.

Nas duas linhas de toras finas, os diâmetros são inferiores a $18 \mathrm{~cm}$, e as costaneiras oriundas do processo, quando estão sem casca, são picadas e os cavacos vendidos para a fabricação de celulose.

A madeira serrada produzida nas serrarias é seca, classificada e vendida ou encaminhada para a fabricação de painéis sarrafeados.

O resíduo produzido durante o processo é captado por correias transportadoras localizadas em um piso inferior em cada ponto de geração de resíduos e encaminhado para o pátio de cavacos da caldeira, para a queima e geração de energia térmica e elétrica. 


\section{Coleta de dados}

Para a avaliação da indústria foram inicialmente realizadas algumas visitas à empresa que tiveram como objetivo o conhecimento e descrição da cadeia produtiva e dos fatores geradores de resíduos. Ainda com base nas visitas, foram elaborados questionários para verificar a necessidade de coleta de dados em campo e a existência de dados da indústria que pudessem ser utilizados no trabalho.

Assim, foi determinado que os dados de escritório da indústria eram confiáveis e suficientes para o desenvolvimento do trabalho, devido a empresa manter registros diários e mensais dos volumes de entrada de matéria-prima e saída de produtos, com pouca variabilidade nos dados ou quando esta ocorria era rastreada e justificada. Além disso, o registro dos dados estava sendo feito a mais de quatro anos. A partir daí foi estabelecida uma série histórica com um intervalo de dados de
18 meses, desde janeiro de 1998 a julho de 1999.

Os dados obtidos em escritório constituíram-se em tabelas de:

- consumo e entrada de matéria-prima em todos os setores da indústria;

- compra de matéria-prima;

- produção;

- estoques;

- e vendas.

De posse destas planilhas, foram determinadas as etapas do processo produtivo que seriam analisadas e o que seria considerado como entradas e saídas no balanço de materiais. Na tabela 3 pode ser visualizado o modelo de planilha utilizado para a análise dos dados, onde foram tabulados os valores volumétricos de cada atividade do processo produtivo considerada (desdobro, secagem, classificação, perdas).

Tabela 3: Organização dos dados obtidos na empresa

Table 3: Organization of the data obtained in the sawmill studied

\begin{tabular}{|c|c|c|c|c|c|}
\hline $\begin{array}{l}\text { Atividade do } \\
\text { processo } \\
\text { produtivo }\end{array}$ & $\begin{array}{l}\text { Consumo de } \\
\text { matéria-prima } \\
(\text { entrada })\left(\mathrm{m}^{3}\right)\end{array}$ & $\begin{array}{c}\text { Compras } \\
\text { (entrada) }\left(\mathrm{m}^{3}\right)\end{array}$ & $\begin{array}{l}\text { Produção } \\
\text { (saída) }\left(\mathrm{m}^{3}\right)\end{array}$ & $\begin{array}{c}\text { Estoques } \\
\text { (entrada) }\left(\mathrm{m}^{3}\right)\end{array}$ & $\begin{array}{c}\text { Venda } \\
\text { (saída) }\left(\mathrm{m}^{3}\right)\end{array}$ \\
\hline Desdobro & Toras & & Madeira serrada verde & Madeira serrada verde & $\begin{array}{c}\text { Madeira serrada } \\
\text { verde }\end{array}$ \\
\hline Secagem & $\begin{array}{c}\text { Madeira serrada } \\
\text { verde }\end{array}$ & Madeira verde & Madeira serrada seca & Madeira serrada seca & $\begin{array}{c}\text { Madeira serrada seca } \\
\text { bruta }\end{array}$ \\
\hline Classificação & $\begin{array}{l}\text { Madeira serrada } \\
\text { seca }\end{array}$ & Madeira seca & $\begin{array}{l}\text { Madeira serrada } \\
\text { classificada }\end{array}$ & Madeira serrada classificada & $\begin{array}{l}\text { Madeira serrada } \\
\text { classificada }\end{array}$ \\
\hline Perdas & & & $\begin{array}{l}\text { Casca, serragem, } \\
\text { costaneiras, refilos e } \\
\text { destopos }\end{array}$ & Resíduos verdes & $\begin{array}{l}\text { Resíduos verdes } \\
\text { (cavacos celulose) }\end{array}$ \\
\hline
\end{tabular}

\section{Determinação do rendimento e quantificação dos resíduos no processo produtivo}

O trabalho foi feito com base no princípio do balanço de materiais, que consiste na determinação de todas as entradas (matériaprima, compra de materiais e estoques) e saídas (produtos intermediários e finais, vendas de produtos e resíduos) do processo produtivo industrial e também com base na relação entre a quantidade de produto que sai e quantidade de matéria-prima que entra no processo.

Sendo assim, o trabalho se constitui em uma mescla de balanço de materiais e análise de rendimento. Porém, para o balanço de materiais não foram considerados todos os insumos que entram na produção (adesivos, resinas, etc), limitando-se apenas à avaliação da matéria-prima madeira, como pode ser observado nas relações de entradas e saídas do processo.

Outro aspecto que deve ser observado é o fato de serem consideradas na avaliação somente as operações que geram resíduos ou perdas. Além disso, como vendas (consideradas também como saídas), foram consideradas somente as realizadas durante as fases intermediárias do processo, ou seja, as vendas de madeira serrada verde e seca.

Equações do rendimento do processo produtivo e quantificação de resíduos

A elaboração de todas as equações utilizada no trabalho baseou-se no princípio do balanço de materiais e na análise do rendimento, ou seja: 
Entrada - saída $=$ resíduo gerado no processo (disponível para geração de energia)

Os valores de resíduos gerados referem-se somente ao montante disponível para geração de energia. Esta metodologia foi adotada porque a indústria em questão vende parte do resíduo gerado, e o excedente que fica na indústria é utilizado somente para a geração de energia.
Assim, nas equações de determinação da quantidade de resíduos gerados, os resíduos vendidos foram subtraídos do total de resíduos gerados.

Rendimento de cada operação do processo produtivo $=$

volume de produto que sai do processo x 100 volume de matéria-prima que entra

As referidas equações estão representadas nas tabelas 4 e 5 .

Tabela 4: Equações para a determinação do balanço de materiais

Table 4: $\quad$ Equations for material balance determination

\begin{tabular}{|c|c|c|}
\hline Operação ou produto & Variáveis envolvidas & Equação \\
\hline $\begin{array}{c}\text { Desdobro } \\
\text { (disponível para energia) }\end{array}$ & $\begin{array}{l}\text { Resíduos do desdobro das toras }=(\text { volume de } \\
\text { toras com casca que entram na serraria) }- \\
\text { (volume de madeira serrada verde }+ \text { volume } \\
\left.\text { de resíduos vendidos para celulose }^{1}\right)\end{array}$ & $\mathrm{RD}=\mathrm{TES}-(\mathrm{MSV}+\mathrm{RVC})$ \\
\hline Secagem $^{2}$ & $\begin{array}{l}\text { Perdas na secagem da madeira serrada }= \\
\text { (volume de madeira serrada verde }+ \text { estoque } \\
\text { anterior de madeira verde }+ \text { volume de } \\
\text { madeira verde comprada) - (volume de } \\
\text { madeira verde vendida }+ \text { volume de madeira } \\
\text { saída do secador) }\end{array}$ & $\mathrm{RSM}=(\mathrm{MSV}+\mathrm{EaMV}+\mathrm{MVC})-(\mathrm{MVV}+\mathrm{MSS})$ \\
\hline Classificação de madeira & $\begin{array}{l}\text { Resíduos da classificação da madeira serrada } \\
=\text { (volume de madeira saída do secador }+ \\
\text { estoque anterior de madeira seca }+ \text { volume de } \\
\text { madeira seca comprada) - (volume de madeira } \\
\text { classificada }+ \text { volume de madeira bruta } \\
\text { vendida) }\end{array}$ & $\mathrm{RCM}=(\mathrm{MSS}+\mathrm{EaMS}+\mathrm{MSC})-(\mathrm{MC}+\mathrm{MBV})$ \\
\hline Madeira seca classificada & $\begin{array}{l}\mathrm{m}^{3} \text { de resíduos } / \mathrm{m}^{3} \text { de madeira seca } \\
\text { classificada }=(\text { volume de toras com casca que } \\
\text { entra no processo para a geração de } 1 \mathrm{~m}^{3} \text { de } \\
\text { madeira seca classificada }-1 \mathrm{~m}^{3} \text { de madeira } \\
\text { seca classificada) }\end{array}$ & $\begin{array}{c}\mathrm{m}^{3} \text { de resíduos } / \mathrm{m}^{3} \text { de } \mathrm{msc}=\left(\text { TET } / \mathrm{m}^{3} \text { de } \mathrm{msc}\right. \\
\left.-1 \mathrm{~m}^{3} \text { de } \mathrm{msc}\right)\end{array}$ \\
\hline
\end{tabular}

1 - Quando havia resíduos vendidos para celulose as toras entravam no processo descascadas, porém, o volume de cascas foi contabilizado no volume de resíduos, porque a casca do descascador vinha através de correias para a serraria e dali para o pátio de cavacos da caldeira.

2 - As perdas que ocorrem durante o processo de secagem são referentes a perda de água e de volume devido a contração (as perdas na secagem não foram contabilizadas no volume total de resíduos pois não se constituem como tal). 
Tabela 5: Equações para a determinação do rendimento do processo produtivo

Table 5: Equations for production yield determination

\begin{tabular}{|c|c|c|}
\hline Operação ou produto & Variáveis envolvidas & Equação \\
\hline Desdobro & $\begin{array}{l}\text { Rendimento do desdobro das toras = (volume } \\
\text { de madeira serrada verde/volume de toras } \\
\text { que entram na serraria)x } 100 \text {. }\end{array}$ & $\mathrm{Rd}=(\mathrm{MSV} / \mathrm{TES}) \times 100$ \\
\hline Secagem & $\begin{array}{l}\text { Rendimento da secagem da madeira serrada } \\
=\text { volume de madeira saída do } \\
\text { secador/(volume de madeira serrada verde + } \\
\text { estoque anterior de madeira verde + volume } \\
\text { de madeira verde comprada - volume de } \\
\text { madeira verde vendida)) } 100\end{array}$ & $\begin{array}{c}\mathrm{Rsm}=\mathrm{MSS} /(\mathrm{MSV}+\mathrm{EaMV}+\mathrm{MVC}- \\
\text { MVV)x100 }\end{array}$ \\
\hline $\begin{array}{l}\text { Classificação de } \\
\text { madeira serrada }\end{array}$ & 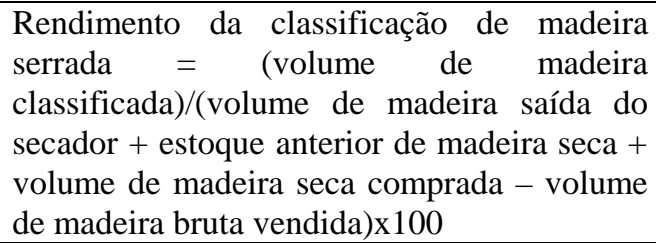 & $\begin{array}{c}\mathrm{Rcm}=\mathrm{MC} /(\mathrm{MSS}+\mathrm{EaMS}+\mathrm{MSC}- \\
\mathrm{MBV}) \times 100\end{array}$ \\
\hline Serraria (geral) & $\begin{array}{l}\text { Rendimento geral da serraria }=\text { (volume de } \\
\text { madeira classificada) } /(\text { volume de toras com } \\
\text { casca que entram na serraria }+ \text { volume de } \\
\text { madeira verde comprada }+ \text { volume de } \\
\text { madeira seca comprada }- \text { volume de madeira } \\
\text { verde vendida }- \text { volume de madeira seca } \\
\text { bruta vendida) } 100\end{array}$ & $\begin{array}{c}\mathrm{Rgs}=(\mathrm{MC}) /(\mathrm{TES}+\mathrm{MVC}+\mathrm{MSC}-\mathrm{MVV}- \\
\mathrm{MBV})) \times 100\end{array}$ \\
\hline $\begin{array}{l}\text { Madeira seca } \\
\text { classificada }\end{array}$ & $\begin{array}{l}\mathrm{m}^{3} \text { de toras para produção de madeira seca } \\
\text { classificada }=100 / \text { rendimento geral da } \\
\text { serraria }\end{array}$ & $\begin{array}{c}\mathrm{m}^{3} \text { de toras para produção de } \mathrm{msc}= \\
100 / \operatorname{Rgs}\end{array}$ \\
\hline
\end{tabular}

\section{Elaboração dos fluxogramas do balanço de materiais}

Para possibilitar a avaliação do balanço de materiais foi elaborado um fluxograma com base na linha produtiva da serraria.

O fluxograma se inicia com a entrada da matéria-prima no setor, que neste caso são toras com casca. A partir da entrada, a seqüência do processo é dada sempre pela atividade ou equipamento envolvido no processo produtivo (desdobro, secagem e classificação da madeira serrada).

A matéria-prima, após passagem pela atividade produtiva tem dois caminhos. O lado esquerdo do fluxograma é representado pela saída dos produtos e sua destinação (venda e/ou estoque), e o lado direito para a saída dos resíduos gerados durante o processo e sua destinação (venda e/ou geração de energia).

Cada item componente dos fluxogramas contém a média mensal do volume produzido do período (produto ou resíduo), representada pela letra "x". Após a média mensal é colocado um valor percentual correspondente ao rendimento da etapa produtiva imediatamente anterior aquele valor.

\section{RESULTADOS E DISCUSSÕES}

\section{Caracterização do resíduo gerado na serraria}

$\mathrm{Na}$ serraria de toras grossas o primeiro ponto de geração de resíduos foi na correia transportadora das toras para o carro da serra de fita dupla. Neste local, parte da casca das toras se solta e cai na primeira esteira transportadora da linha de produção. O segundo ponto é a própria serra de fita dupla, onde o principal resíduo é a serragem da retirada das costaneiras. As demais serras do processo de transformação, tanto da serraria de toras grossas com a de toras finas, também geram o mesmo tipo de resíduo (serragem). As serras de fita do reaproveitamento geram costaneiras com casca, após a retirada das tábuas, que através de correias transportadoras vão para o picador de tambor.

As serras circulares que fazem o refilo e o destopo das tábuas do reaproveitamento 
geram peças retiradas no processo de determinação da largura e comprimentos finais das tábuas de aproveitamento (refilos e destopos).

Quando o descascador está em atividade, o resíduo gerado pelas costaneiras das linhas de toras finas não tem casca, sendo destinado para o picador com rotor que reduz o material em cavacos que são vendidos para celulose. Quando o descascador não está funcionando as costaneiras são picadas para a geração de energia.

A casca retirada das toras no descascador também é encaminhada para a primeira esteira da serraria, que leva o material para o pátio de cavacos da caldeira.

\section{Determinação do rendimento e quantificação dos resíduos do processo produtivo}

O fluxograma da figura 2 é composto por todas as entradas e saídas do processo produtivo de madeira serrada seca classificada.

Vale salientar que se observando o fluxograma da figura 2 alguns valores apresentados não correspondem às porcentagens relacionadas a eles. Porém, este fato é devido ao uso dos valores médios encontrados para o intervalo de tempo analisado. Esta observação serve também para as tabelas e figuras que aparecerão subseqüentemente.
O balanço foi constituído a partir dos passos produtivos da serraria que são desdobro, secagem e classificação. A serraria é o setor da indústria com maior volume de resíduos gerados, devido ao grande volume de madeira processado e também ao baixo rendimento apresentado pela atividade de desdobro das toras.

Através da figura 2 pode-se perceber que de uma forma geral os valores de rendimento são baixos, tanto para o desdobro, como para a secagem e classificação de madeiras.

Assim, todo o resíduo produzido neste setor é verde (desdobro das toras), porém devido à separação do resíduo em correias transportadoras com destinos distintos, há grande potencial para a utilização ou venda dos resíduos para outros fins além da geração de energia.

A tabela 6 apresenta os valores de entrada de matéria-prima, saída de produtos e resíduos e rendimento de cada atividade do setor, além do rendimento geral do mesmo.

Para permitir melhor análise do valor de rendimento da serraria foi construída a tabela 7, na qual os valores obtidos na empresa foram comparados com valores de autores que realizaram trabalhos similares em indústrias de base florestal.

Tabela 6: Dados médios de cada processo da serraria durante o período avaliado (1998/1999)

Table 6: $\quad$ Medium data of each process in the sawmill, from 1998 to1999

\begin{tabular}{ccccrrrrr}
\hline \multirow{2}{*}{ Operação } & \multicolumn{2}{c}{$\begin{array}{c}\text { Entrada } \\
\end{array}$} & \multicolumn{3}{c}{ Matéria-prima $\left(\mathrm{m}^{3}\right)$} & \multicolumn{1}{c}{ Saída do Produto $\left(\mathrm{m}^{3}\right)$} & Saída de Resíduo $\left(\mathrm{m}^{3}\right)$ & \multicolumn{2}{c}{$\begin{array}{c}\text { Rendimento da } \\
\text { Produção }(\%)\end{array}$} \\
\hline & \multicolumn{1}{c}{ Média } & \multicolumn{1}{c}{ DP } & \multicolumn{1}{c}{ Média } & \multicolumn{1}{c}{ DP } & \multicolumn{1}{c}{ Média } & \multicolumn{1}{c}{ DP } & \multicolumn{1}{c}{ Média } & DP \\
\cline { 2 - 9 } Desdobro & 25668,76 & 2136,76 & 8945,55 & 768,18 & 16723,21 & 1522,67 & 34,87 & 1,54 \\
Secagem & 12503,69 & 1183,84 & 10281,81 & 1102,93 & 2273,82 & 762,70 & 81,88 & 5,49 \\
Classificação & 11980,60 & 1373,13 & 10312,82 & 944,98 & 1667,79 & 774,65 & 86,42 & 5,13 \\
Geral & 25668,76 & 2136,76 & 10312,82 & 944,98 & $16723,21^{1}$ & 774.65 & 38,62 & 4,29 \\
\hline
\end{tabular}

$\mathrm{DP}=$ desvio padrão.

1 - A somatória geral dos resíduos não considerou a perdas da secagem (não são resíduos como anteriormente mencionado) e os resíduos da classificação de madeiras, pois esta atividade é realizada no setor de produção de painéis e o resíduo entra na contabilização daquele setor, para efeito de quantificação. 


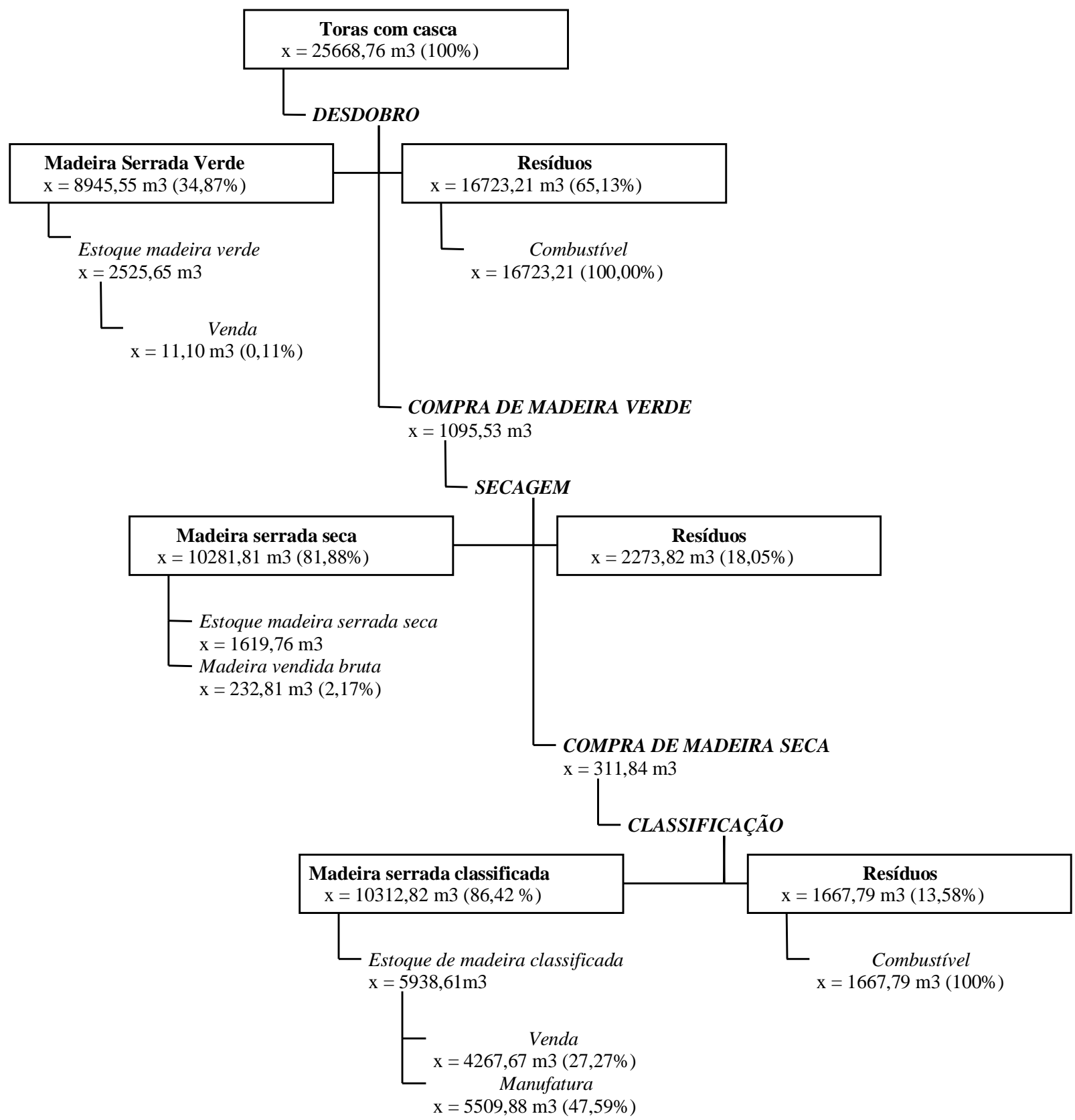

Figura 2: Fluxograma do balanço de materiais da serraria ${ }^{1}$

Figure 2: Sawmill material balance

\footnotetext{
${ }^{1}$ Como na entrada das toras na Serraria é determinado o diâmetro sem casca, para os cálculos de rendimento e geração de resíduos, bem como para a determinação do rendimento geral da serraria foi acrescido ao valor fornecido pela empresa, um valor correspondente a $12 \%$, o que eqüivale em média a porcentagem de casca para o Pinus.
} 
Tabela 7: Dados comparativos do rendimento da serraria

Table 7: Comparative data of sawmill yield

\begin{tabular}{cccc}
\hline & Madeira serrada verde & $\begin{array}{c}\text { Madeira serrada seca } \\
\text { classificada }\end{array}$ & $\begin{array}{c}\text { \% } \\
\text { resíduos }\end{array}$ \\
\hline Serraria estudada & $34,87^{*}$ & 38,62 & $65,13^{*} 61,38$ \\
BRITO (s/d) & - & 42,34 & 57,66 \\
KOCK (1976) & - & 35,00 & 65,00 \\
MIYAZAKI (1989) & 68,80 & - & 31,2 \\
OLANDOSKI et al. (1997) & 49,00 & - & 51,00 \\
BORGES (1993) & 52,27 & - & 47,73 \\
\hline
\end{tabular}

* Este valor considera somente o rendimento do desdobro.

Através da avaliação da tabela 7 podese perceber que os valores obtidos neste trabalho estão bem próximos dos obtidos por Brito (s/d) no Brasil, para madeira serrada seca e classificada e também aos dados de Kock (1976), que trabalhou com coníferas nos Estados Unidos. Para rendimento em madeira verde, os valores deste trabalho se aproximam mais ao encontrado por Olandoski et al (1997), que também trabalharam no Brasil com desdobro de Pinus.

O rendimento em madeira verde deste trabalho apresentou-se menor provavelmente devido à técnica moderna de desdobro utilizada pela indústria. Por exemplo, no trabalho desenvolvido por Olandoski et al. (1997), foi utilizada a técnica convencional de desdobro (desdobro principal em serra-fita, refilo em serra circular de mesa e destopo em serra circular pendular), com grande variação nos diâmetros desdobrados, porém com tratamento individualizado para o desdobro de cada tora. Este fato consequentemente acarreta em rendimento maior. Porém, quando é incluída no cálculo, a secagem e classificação da madeira, a diferença diminui entre os autores estudados e o trabalho.

Com relação aos resíduos gerados na serraria, no período avaliado, todo o resíduo foi destinado para a geração de energia, sendo que ao final deste período estava sendo instalado um silo para a venda de parte do resíduo sem casca para indústrias de celulose. Neste sentido, Kock (1976) afirma que a quantidade de resíduos a ser destinado para a obtenção de celulose pode representar $29 \%$ da quantidade de matéria-prima que entra no processo.

\section{Consumo de matéria-prima e quantidade de resíduo gerado por $\mathrm{m}^{3}$ de produto}

Constatou-se que são necessários 2,62 $\mathrm{m}^{3}$ de toras com casca para a produção de $1 \mathrm{~m}^{3}$ de madeira serrada seca classificada. Portanto, existe a produção de $1,62 \mathrm{~m}^{3}$ de resíduos no processo.

Segundo Kock (1976), são necessárias 2,86 toneladas de toras secas com casca para a manufatura de 1 tonelada de madeira serrada seca.

Como a unidade de medida utilizada por este autor foi diferente da utilizada neste trabalho, foi feita uma transformação para a mesma unidade de medida (toneladas de toras secas/tonelada e madeira serrada seca) utilizando-se o valor da massa específica aparente básica para o Pinus de $415 \mathrm{~kg} / \mathrm{m}^{3}$ (Klock et al, 2000), e a massa específica aparente de $450 \mathrm{~kg} / \mathrm{cm}^{3}$ (12\% de umidade), usualmente utilizada como média para espécies de Pinus.

Utilizando-se a equação para determinação da massa específica, com estes valores de massa específica e o valor de consumo de matéria-prima do trabalho pode-se chegar a conclusão que é necessária 2,42 toneladas de toras secas com casca para produzir 1 tonelada de madeira serrada seca, sendo que este valor está próximo ao encontrado por Kock (1976).

A determinação deste fator de conversão é muito importante para a determinação da quantidade de resíduo e planejamento das atividades em uma serraria. Por exemplo, se a produção mensal de madeira serrada seca classificada for de $10.300 \mathrm{~m}^{3}$, saber-se-á que também será produzido um volume de $16.686 \mathrm{~m}^{3}$ de resíduo, que é o caso da empresa avaliada. 
Além disso, poder-se-á comercializar $7.825,94 \mathrm{~m}^{3}$ deste material para a produção de celulose, se for considerada a afirmação de Kock (1976) de que é possível comercializar até $29 \%$ de toda a matéria-prima que entra na serraria para a produção de celulose (entram $26.986 \mathrm{~m}^{3}$ de toras para a produção de 10300 $\mathrm{m}^{3}$ de madeira serrada seca e classificada), restando ainda $8.860 \mathrm{~m}^{3}$ de resíduo para ser utilizado na geração de energia ou para outra finalidade.

\section{CONCLUSÕES}

- Os rendimentos das atividades do processo produtivo da serraria (desdobro, secagem e classificação de madeiras) são baixos.

- Considerando somente o desdobro, o rendimento é muito inferior aos valores encontrados por outros autores que trabalharam com Pinus.

- Considerando o rendimento geral da serraria, apesar de ser baixo, está dentro dos valores aceitos para este ramo do setor industrial florestal e se aproxima mais dos valores encontrados por outros autores.

- Todo resíduo produzido no setor é verde e tem grande potencialidade de utilização para outros usos além da energia, devido a separação dos mesmos durante o processo produtivo.

- A instalação do picador e silo para venda de cavacos sem casca para celulose, que estava sendo realizada no final do período de coleta de dados, proporciona redução do estoque de resíduos verdes da serraria, otimiza o uso e agrega valor ao resíduo gerado pela indústria.

- O fato de conversão de toras em madeira serrada possibilita o controle do volume de matéria-prima necessária e o volume de resíduo que será gerado em determinado período de análise.

\section{REFERÊNCIAS}

ANUÁRIO BRASILEIRO DE ECONOMIA FLORESTAL. Aproveitamento dos resíduos de serraria. Vol 9. 1957. p 97-98.

BORGES, A.S.; GINIGLIO, G. \& BRITO, J.O. Considerações energéticas e econômicas sobre resíduos de madeira processada em serraria. $\quad \mathbf{1}^{\mathbf{0}}$ Congresso $\quad$ Florestal Panamericano e $7^{\circ}$ Congresso Florestal
Brasileiro. 19 a 24 de setembro. Vol 3, Curitiba, 1993. p. 603-606.

BRITO, E.O. Estimativa da produção de resíduos na indústria brasileira de serraria e laminação. Revista Floresta. Vol 26, Ano IV. p. 34-39.

C.T. DONOVAN ASSOCIATES INC. Opportunities and Constraints Associated with Using Wood Waste for Fuel in Connecticut. Office of Policy and Management, Energy Division. Connecticut, 1990.

HOOP, C.F. DE; KLEIT, S.; CHANG, S.J.; GAZO, R. \& BUCHART, M.E. Survey and mapping of wood residue users and producers in Louisiana. Forest Products Journal 47 (3), 1997. p. 31-37.

JARA, E.R.P. A geração de resíduos pelas serrarias. Boletim ABNT $n^{\circ}$ 59. São Paulo: IPT, 1987.

KLOCK, U.; MATOS, J.L.M.; MUÑIZ, G.I.B.; BITTENCOURT, E.; ANDRADE, A.S.; VERONESE, P.A. \& OLIVEIRA, A.C. Densidade básica da madeira ao longo do fuste na madeira juvenil de Pinus taeda L. e Pinus maximinoi H. E. Moore. Pesquisa Florestal Online. Curitiba, 2000. p. 165.

KOCK, P. Material balances and energy required for manufacture of ten wood commodities. Energy and the wood products industry. Forest Products Research Society. Georgia, 1976. 173p.

MIYAZAKI, M. Forestry products and waste. Biomass Handbook. Editors KITANI, O. \& HALL, C.W. New York: Gordon and Breach Science Publishers. USA, 1989. p. 160-170.

NATIONAL ASSOCIATION OF FOREST INDUSTRIES. Forest Today. woodchips. Disponível:www.nafi.com.au/faq/woodchips. html. Capturado em outubro de 1999.

OLANDOSKI, D.P.; BRAND, M.A. \& GORNIAK, E. Avaliação do rendimento, quantidade, qualidade e aproveitamento de resíduos no desdobro de Pinus spp. 5o EVINCI - Evento de Iniciação Científica da UFPR. Curitiba, 1997. p. 379.

PATZAK, W. Energia da madeira e de resíduos: estágio atual da pesquisa e da prática 


\section{na Alemanha ocidental. Seminário FLORESTA: potencial energético} brasileiro, 1977. p. 73-83.

ROCHA, M.P. Desdobro Primário da Madeira. FUPEF - Série Didática no 02/99. Curitiba, 1999. $61 \mathrm{p}$.

SOUZA, MR. Tecnologias para usos alternativos de resíduos florestais: experiência do laboratório de produtos florestais - IBAMA na área de utilização de resíduos florestais e agrícolas. Workshop Sul-Americano sobre usos alternativos de resíduos de origem florestal e urbana. Curitiba, 1997. p. 49-70.

TUSET, A. \& DURAN, F. Manual de Madeiras Comerciales, Equipos y Processo de Utilizacions. Uruguai, Editorial Hemisfério Sul, 1979.

\section{AGRADECIMENTOS}

À Universidade Federal do Paraná pela oportunidade de realização do trabalho e à Coordenação de Aperfeiçoamento de Pessoal de Nível Superior (CAPES) pela bolsa concedida.

À empresa Battistella Indústria e Comércio Ltda. pelo fornecimento dos dados, sem os quais não seria possível o desenvolvimento deste trabalho e em especial para o Sr. Odelir Battistella, Lázaro Tadeu da Silva e Joel de Aviz pelo apoio, conselhos e dedicação para fornecer todas as informações necessárias para o desenvolvimento do trabalho. 